\title{
Adapting to extreme events: small drinking water system manager perspectives on the 2012-2016 California Drought
}

\author{
Meghan Klasic $^{1,2} \cdot$ Amanda Fencl $^{2,3} \cdot$ Julia A. Ekstrom ${ }^{1,4} \cdot$ Amanda Ford $^{5}$
}

Received: 22 July 2021 / Accepted: 28 December 2021 /Published online: 11 February 2022

(c) The Author(s) 2022

\begin{abstract}
Under a changing climate, droughts are projected to increase in frequency and duration in the Southwestern USA. Between 2012 and 2016, California experienced one of the region's worst droughts, with record high temperatures and low snowpack, runoff, and precipitation. This study documents small drinking water system managers' experiences during the 2012-2016 Drought. We contribute to research on water system drought resilience by elevating small drinking water system manager perspectives and expertise. We are especially focused on small systems that are not reliant on imports from state or federal water projects. A mixed-method approach ensures each data collection period informs the next to gather statewide perspectives and experiences of managers.

Based on an analysis of drinking water manager reflections, the types of impacts, responses, and barriers differed based on both system size and water source portfolio. Common disadvantages that hinder small drinking water systems' drought resilience and, similarly, climate adaptation include staff and administrative capacity; the financial burden of promoting water conservation over revenue compounded by onerous reporting and funding support programs; consumer awareness challenges; and challenges to consolidation from both local political differences and physical limitations. Systems that built technical, managerial, or financial capacity prior to the Drought were at an advantage over systems that lacked this capacity. In the long term, we found a dearth of adaptation planning among small water systems. Documentation of experiences from the 2012-2016 Drought can inform future planning for droughts and more broadly highlight needs for climate adaptation.
\end{abstract}

Keywords Drought $\cdot$ Climate adaptation $\cdot$ Drinking water $\cdot$ Small drinking water systems $\cdot$ Disadvantaged communities $\cdot$ Climate justice $\cdot$ Extreme events

Meghan Klasic

mrklasic@ucdavis.edu

UC Davis Policy Institute for Energy, Environment, and the Economy, Davis, CA, USA

Center for Environmental Policy and Behavior, UC Davis, Davis, CA, USA

Department of Geography, Texas A\&M University, College Station, TX, USA

California Department of Water Resources, Sacramento, CA, USA

5 Riverford Consulting, Sacramento, CA, USA 


\section{Introduction}

Climate change is increasing the frequency and severity of extreme weather-related events globally, leading to disastrous impacts on natural resources, infrastructure, and services on which people rely. Drinking water suppliers in California face challenges from continued and future droughts and other extreme events; climate change is expected to amplify these threats. A recent extreme event, the 2012-2016 + Drought in California (hereafter referred to as "the Drought"), was intense both in terms of its social and physical impacts. The Drought offers the opportunity to learn from an extreme event that is expected to become more frequent and severe with climate change and population growth (Swain et al. 2018; Diffenbaugh et al. 2015; Seager et al. 2015; Williams et al. 2015).

The goal of this research was to document empirically small, self-sufficient drinking water system managers' perspectives, experiences, and needs for future drought resilience in the face of climate change and uncertainty. In this paper, we define self-sufficient water systems as those that do not purchase or otherwise receive any water from the State Water Project (state operated) or from the Central Valley Project (federally operated). In our research, we underscore the importance of learning from local water system managers themselves to gain insight into what drinking water systems need for climate adaptation to reduce future risks. Five key questions guided this study:

1. How did small drinking water systems experience the Drought?

2. Did small drinking water systems experience the Drought differently from larger systems?

3. What are small drinking water systems' needs for climate adaptation?

4. Do small drinking water systems' need for climate adaptation differ from larger systems?

5. How did the state's Drought policies and processes relate to small drinking water systems' impacts and responses?

We begin by giving an overview of California water management and the policy context of the Drought before turning to a brief discussion of the literature on drinking water manager perspectives. Following, we review our three-stage methodology and findings. Finally, we discuss the implications of our findings for ongoing and future California water management, small systems' resilience, and approaches to drought adaptation.

\subsection{The 2012-2016 Drought in California}

California has a Mediterranean climate characterized by warm dry summers and cold wet winters with periodic dry spells. Because of the wide variability in precipitation from year to year, California relies on several major rainstorms annually, combined with a network of storage, to overcome dry periods (Dettinger 2013, 2011). The state's highly engineered system of transporting water through the State Water Project (SWP) ${ }^{1}$ and the Central Valley Project $(\mathrm{CVP})^{2}$ moves water through a system of reservoirs and canals from the

\footnotetext{
1 The SWP transports water more than 700 miles from northern to southern California and has been in operation since 1962 (DWR 2021a).

2 The CVP includes 20 dams and reservoirs and more than 500 miles of canals, tunnels, etc. operated by the US Bureau of Reclamation since 1940 (USBR 2021).
} 
Sacramento-San Joaquin River Delta to urban centers and agricultural regions throughout the state. The southwest region of the US faces periodic droughts; however, the period between 2012 and 2014 was the most severe drought in the region for the past 1200 years (Griffin and Anchukaitis 2014). While the lower rainfall and soil moisture deficits during the Drought were within California's range of natural variability, the long warming trend and record high temperatures intensified its impacts (Berg and Hall 2015; Diffenbaugh et al. 2015; Seager et al. 2015; Williams et al. 2015).

During droughts, reduced availability of surface water pushes users to increase their reliance on groundwater sources, when available (Bostic 2021). Competing uses can impact the availability of groundwater for domestic use in rural communities. A common consequence of the state's increased reliance on groundwater during dry years is overdraft and subsequent subsidence, which negatively affects isolated rural communities that have few supply alternatives to groundwater. During the Drought, groundwater dropped to or below historically low levels in more than one-third of Sacramento Valley wells and more than half of Central Valley wells (Jasechko and Perrone 2020; Pauloo et al. 2020; DWR 2014). The Drought also motivated the adoption of the Sustainable Groundwater Management Act (SGMA) in 2014 to help better manage this critical resource.

The Drought exacerbated the vulnerability of drinking water suppliers, particularly small and rural systems that tend to have limited capacity to respond to drought and other emergencies (Conrad 2013; DWR 2010). Even in 2010, the state recognized that "a few hundred of the roughly 4000 smaller water companies in the state face running dry in the second or third year of a drought" (DWR 2010, p. 56). Many systems also face increased water quality problems during dry periods. As climate change amplifies drought risks, drinking water systems must find a way to manage water supply and maintain quality for immediate needs and the future.

To respond to the Drought, California Governor Brown declared a drought state of emergency (Exec. Order B-17-2014) in January 2014 and, by April 2015, introduced a statewide policy of mandatory water reductions (Exec. Order B-29-2015). While a limited number of governmental and nongovernmental organizations have ongoing programs to support small water systems, the sheer quantity of small systems in California created a need to document and reflects on their drought experiences.

Learning from the recent experience of water systems during the Drought becomes even more relevant as California reenters an extreme drought and there is increasing attention for supporting small water systems. After declaring a drought emergency in spring 2021, Newsom proposed billions in targeted investments for immediate drought response and long-term resilience support for water infrastructure (Newsom 2021; Office of the Governor 2021a). With Governor Newsom's signing of the Drought Planning: Small Water Supplier (SB 552) in September 2021, a subset of small water suppliers and schools are now required to develop water shortage contingency plans with specific drought elements (California Senate 2021). Additionally, all small water systems must incorporate drought planning into their emergency response plans and meet new infrastructure requirements activated over the next decade. As part of a \$15 billion California Comeback Plan (Office of Governor 2021b), \$200 million has already been distributed through the Small Community Drought Relief Program. This program was designed to offer financial and technical assistance to small communities facing water supply challenges because of the current drought (DWR 2021b). As of October 2021, funds supported water hauling, extended surface water intakes, and provided other relief to small systems to adapt to drought-induced shortages. This suite of recent drought-focused actions is layered onto an existing policy priority to achieve the state's 2012 Human Right to 
Water for all Californians (AB 685) (SWRCB 2021) and resolve California's ongoing drinking water quality crisis (Balazs et al. 2021, 2011).

\subsection{Small drinking water systems, drought, and climate change}

As with most natural resource management, water management agencies have a history of acting reactively rather than proactively to extreme events, hindering their capacity to adapt to climate change (Wilhite and Pulwarty 2017; Engle 2013; DWR 2008, 2011). Over the past decade, scholars and California's water management agencies have called for the adoption of a proactive drought management approach (Rossi and Cancelliere 2013; DWR 2011). Learning from the knowledge and perspectives of, and examining managers' responses to, extreme events like drought, provides a method to understand what systems need to adapt to a changing climate (Page and Dilling 2020; Dilling et al. 2019; McNeeley et al. 2016; McNeeley 2014; Engle 2012, 2013). This bottom-up approach, or what McNeeley (2014) refers to as a "toad's eye" perspective, provides "critical insights into local manifestations of drought risk and responses to better inform decision making for climate adaptation" (p. 1452).

Drinking water managers experience drought in myriad ways that shape their short- and long-term responses. Expanding the systems' water supply portfolio is one of the most significant actions that managers take (Page and Dilling 2020), yet they must balance both space and time tradeoffs when connecting drought preparedness and adaptation (Engle 2013). For example, drilling new wells to expand supply in the short-term when historic over-reliance on groundwater during droughts can be maladaptive. In other instances, even if a system has the adaptive capacity, barriers may prevent enacting it (McNeeley 2014). Overcoming barriers like political and public acceptance of managers' proposed drought responses becomes just as important as the responses being technically feasible (Hornberger et al. 2015).

In terms of how existing drought management will be affected by climate change, few studies focus on understanding the needs of small water system managers for preparing for climate impacts in high-income countries. A proactive drought adaptation agenda has yet to be implemented to an equal degree across all water systems (Ekstrom et al. 2017; Wilhite and Pulwarty 2017). This paper contributes to the literature on managing drinking water under climate change and fills a need for research on small drinking water systems that are understudied often due to limited data (Dobbin and Fencl 2021; McFarlane and Harris 2018). To fill this need, we gathered perspectives and experiences of drinking water system managers (hereinafter referred to as system managers) to understand the variable ways in which water systems were impacted by and responded to the Drought. Furthermore, we explored the barriers to drought resilience and facilitated policy discussions on how to better align state policy and programs with small system needs. Our research underscores the importance of preparing for and adapting to the increasing frequency and severity of extreme events under in changing climate.

\section{Research design and methods}

There is a growing recognition of the need to employ a bottom-up, social science approach to adaptation like the one being employed in this project (Victor 2015; Mastrandrea et al. 2010). Social science methods can be effective in offering a setting for the dialogue of different stakeholders and for collective input when conducted through group formats. Seeking to capture the needs of water system managers across California, we used an iterative 


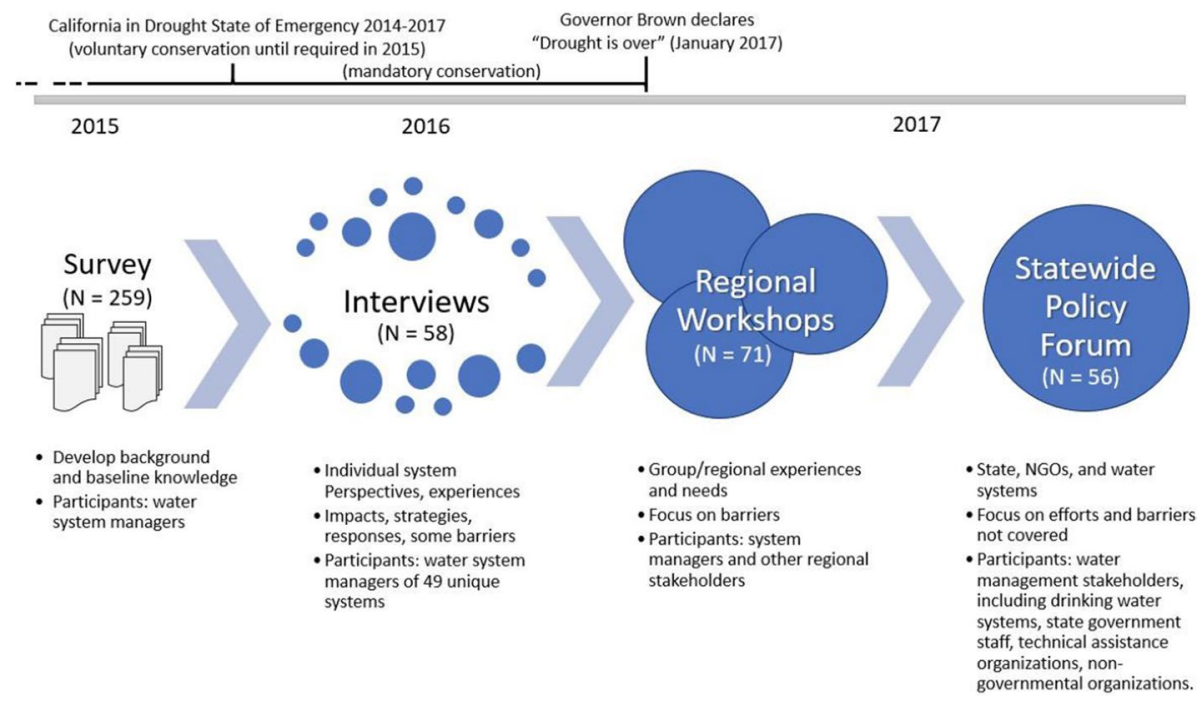

Fig. 1 Timeline of study process and events, indicating significant State of Emergency policy; total participants in this study include 185 individuals across 2 years (excluding the survey respondents)

set of social science methods for data collection and analysis as illustrated in Fig. 1. We initially collected data through an online survey (results analyzed in Ekstrom et al. 2017) that influenced future data collection. This paper analyzes data collected from interviews, a regional workshop series, and a Policy Forum held in Sacramento with policymakers, government and NGO staff, and small system managers (for more information on methods see, Ekstrom et al. (2018)).

The timeline of data collection is notable given that climatic events shaped the experiences and perspectives of participants. The survey of system managers was conducted between July and September 2015 (a few months after an executive order requiring water conservation, Exec. Order B-29-2015). Interviews with system managers were conducted between June and October 2016. The interview period coincided with the extended and revised conservation mandate (May 2016) that required some water systems to (1) self-certify that they had sufficient supplies for three more years and (2) provide a localized reduction target based on a stress test (SWRCB 2016). During the first half of the 2016-2017 water year (Oct. 2016-May 2017), the state received higher than average precipitation, leading the Governor to declare an end to the drought state of emergency in April 2017 for all but four counties (Fresno, Kings, Tulare, and Tuolumne). Regional workshops in June and July 2017 followed the wet winter, but many system managers still felt drought-related impacts. The Policy Forum was held at the end of summer 2017, which allowed for a balance between emergency Drought management and nearing post-Drought reflection.

\subsection{Framing of adaptation}

We employed a similar approach and principles developed in Moser and Ekstrom (2010) and applied in Ekstrom and Moser (2014) to identify the climate change impacts, adaptation strategies, and adaptation barriers. We relied on a similar definition of adaptation, 
as changes in social-ecological systems in response to experienced or anticipated climate impacts, and the adaptation strategies and actions that facilitate changes operate over either or both short- and long-term periods. This definition has also been applied by other scholars (e.g., Ayeb-Karlsson et al. 2016; Herman-Mercer et al. 2016; Archie et al. 2014).

We used the adaptation barriers framework in Moser and Ekstrom (2010) to organize and identify barriers to climate adaptation and to characterize the types of strategies undertaken by system managers during the drought. Examining extreme event impacts and responses offers valuable insight into informing the needs for climate adaptation (Dilling et al. 2017; McNeeley et al. 2016; Engle 2013; Kates et al. 2012; Costanza et al. 2007). Therefore, we documented one recent extreme event - the Drought - to examine a water system's response mechanisms and challenges. This offers a proxy view of the risks and challenges that climate change could bring to these systems (Dilling et al. 2019; McNeeley 2014; Engle 2011). As others have pointed out, there are potential limitations inherent in using past events as analogs. First, by interviewing system managers during the height of the Drought, it is possible we captured more temporary coping strategies than longterm transformative strategies (Ekstrom et al. 2018; Christian-Smith et al. 2015). Second, actions that help system managers adapt to impacts now do not necessarily translate into useful actions for future impacts (Dilling et al. 2015; Engle 2012).

\subsection{Unit of analysis}

The unit of analysis for this study is the drinking water system $(n=49)$. Of the 49 water systems represented, 15 are groundwater reliant, 13 are surface water reliant, and 21 are both groundwater and surface water reliant. We focus specifically on water systems that are both small and self-sufficient (referred to as S3 systems, $n=24$ ). Small systems refer to those serving fewer than 10,000 people, and self-sufficient systems are those that are not reliant on either of the two large government-operated distribution systems (the SWP or the CVP, or project water). For comparison purposes, non-S3 systems refer to water systems that do not meet both previously mentioned criteria $(n=25)$. As such, non-S3 systems include small systems with access to project water $(n=3)$ as well as self-sufficient systems that serve more than 10,000 people $(n=3)$.

\subsection{Three-stage data collection}

Data were collected in three stages, each with unique methods: (1) interviews; (2) regional workshops; (3) Policy Forum. Each stage allowed the research team to validate and build on its findings with different system managers to answer the research questions. Figure 1 summarizes the project stages, the target population, and the number of participants recruited. Across the project stages, the team gathered input from 185 participants. Figure 2 shows the geographic coverage of input from system managers (a) and data collection stages (b). During the first stage of data collection, we interviewed system managers to gather perspectives on, and experiences with, the Drought. During the second stage of data collection, we facilitated regional workshops with system managers and other stakeholders, like county agency staff, nonprofit organizations, and concerned citizens. This stage was used to ground-truth interview findings; the perspectives of non-drinking water system managers were not analyzed as part of this paper. In the final stage of data collection, the Policy Forum convened drinking water stakeholders, including system managers and state 

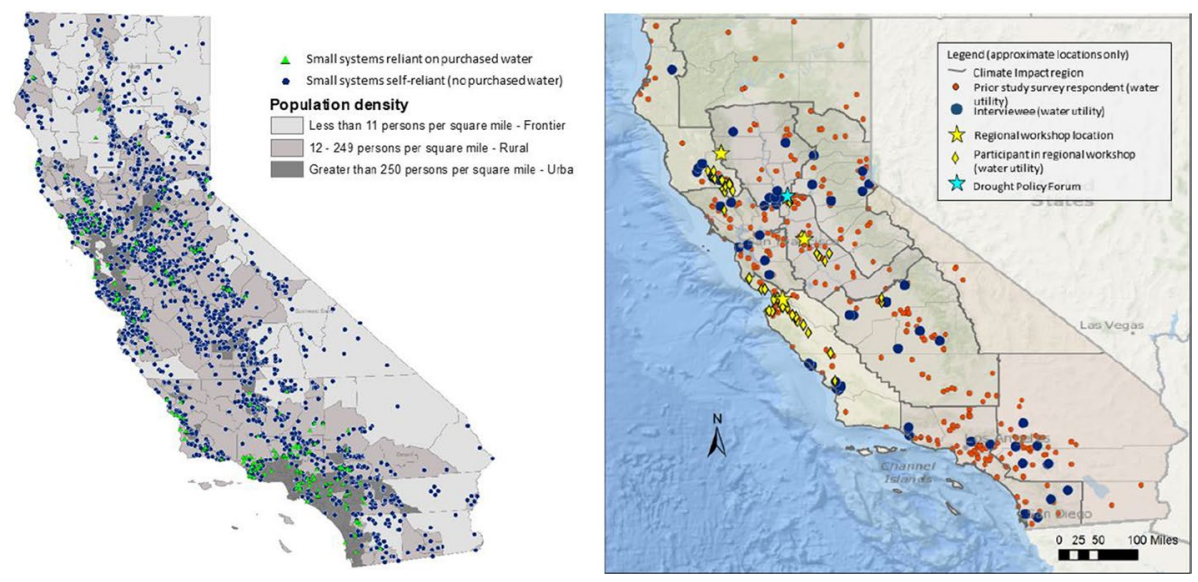

Fig. 2 a Map of small water systems serving 10,000 or fewer people (SWRCB 2016), record of purchased water from SWP or CVP (SWRCB 2014), and population density (U.S. Census Bureau 2016); b approximate locations of water systems that had managers participate in interviews and workshops; and approximate locations of regional workshops and the Policy Forum

and nongovernmental organizations that play critical roles in supporting small water systems; we used the barriers identified in previous data collection stages as fodder to discuss the Drought and small water system needs with an eye toward developing potential solutions (see Online Resource 1).

\subsubsection{Interviews}

The research team conducted 58 in-person and phone interviews with system managers across California. To gather experience representing a diverse set of systems in each geographic region, we identified a representative sample of managers using a coarse typology based on source portfolio, size, and ownership type and reviewed them with key California water informants (see Ekstrom et al. 2018). The interview protocol (see Online Resource 2) was theoretically informed by the climate adaptation barriers framework described in the Moser and Ekstrom (2010). Interview questions covered drought management, climate adaptation perspectives, water quality challenges, and the use of climate information. ${ }^{3}$ Interviews with non-water system entities were excluded from our content analysis.

We inductively coded interview transcriptions using an online content analysis software, Dedoose ${ }^{\circledR}$. Following a coding structure described by Saldaña (2013), the research team developed a primary and sub-code scheme to relate thematic interview responses to the research questions and theory on climate adaptation barriers and information needs (see Online Resource 3). Coded excerpts were reviewed and analyzed inductively into categories based on emergent themes in the data (see Online Resource 4 for thematic categories and definitions).

\footnotetext{
${ }^{3}$ Codes related to the use of climate information and water quality challenges were not used in this analysis. See Baker et al. (2018) for an analysis of climate information codes.
} 


\subsubsection{Regional workshops}

The second stage of data collection sought to share, verify, and build-on interview findings through a collective venue, as suggested by Luyet et al. (2012) and Cornwall (2008). Three regional workshops convened local drinking water experts to review preliminary findings from the interview stage and to gather additional experiences and perspectives. We recruited a key leader in each region to co-host each workshop and invite attendees. A total of 71 people participated in the workshops, including representatives from approximately 37 water systems. We minimized the overlap of systems between the interview and the regional workshop phase. Workshop participants represented system managers and local decision-makers that have direct experience working with small water systems, such as County Environmental Health staff and State Board Drinking Water District Engineers. Workshops were organized in collaboration with and expertly facilitated by, the Environmental Justice Coalition for Water (EJCW), a nonprofit water justice organization working with and empowering underserved communities in California. EJCW was a key partner in identifying and recruiting water managers and justice leaders to participate in the workshops.

\subsubsection{Statewide Policy Forum}

In the third stage of data collection, we convened policymakers and system managers to review and ground truth our findings and to facilitate discussion on potential solutions to small system needs. The Forum on Drought Resilience for Small Water Systems (Policy Forum) was held on September 20, 2017, in Sacramento, CA. The Policy Forum was developed in collaboration with and facilitated by EJCW. In ensuring that the agenda met the needs of local stakeholders and decision makers, EJCW's expert facilitation held space for discussion and reflection. Our partnership with EJCW was crucial to the success of the Policy Forum. Moderators facilitated small group discussions on existing and potential state policy efforts to better align with small drinking water system needs to overcome barriers and achieve drought resilience. In total, 56 state and federal government staff, system managers, nonprofit and philanthropic organizations, and academic researchers participated in the Policy Forum, reflecting the ways in which water policy and small system assistance go beyond government.

\section{Results}

In the sections that follow, we present the impacts of and responses to the Drought as well as the barriers to drought resilience discussed by S3 (small, self-sufficient drinking water system) and non-S3 managers (see Online Resource 4 for category definitions). Then, we present where in the climate adaptation process system managers are currently, followed by the potential solutions to assist system managers that developed during the Policy Forum to overcome barriers to drought resilience in pursuit of long-term climate adaptation. As part of this final section, we present the benefits of system managers' taking actions prior to the Drought for adaptive capacity and what future actions system managers want to pursue to build drought resiliency. 


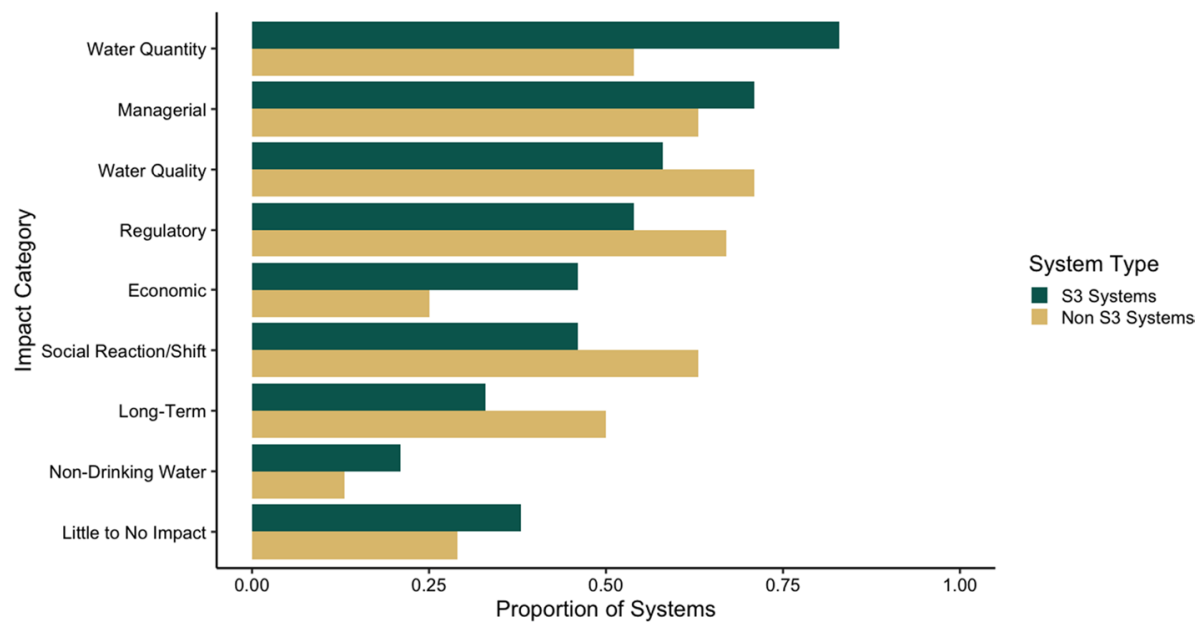

Fig. 3 Drought impact categories by system type (categories were inductively developed and are defined in Online Resource 4)

\subsection{Drought impacts}

The Drought impacted drinking water systems in myriad ways. Of the 49 system managers interviewed, all but two (both non-S3 managers) reported some type of Drought impact (Fig. 3). Across all systems, the top impact categories were water quantity (70\%), managerial $(68 \%)$, water quality $(66 \%)$, and regulatory $(62 \%)$. These top categories are consistent with the discussion results from regional workshops. S3 managers most frequently reported water quantity impacts (83\%) like reduced streamflow and dry lakes and voiced concerns over how to address potential further depletion. Among groundwater users, wells sometimes become obsolete, requiring deeper digging or new placement, while surface water intakes need to be placed lower in water sources. With these changes, S3 managers reported water quality issues (58\%), like deeper wells showing increases in arsenic and manganese and surface water sources experiencing larger algal blooms. Notably, non-S3 managers reported more water quality issues (74\%), although they were mostly due to project water curtailments that forced a shift from their primary water source to a backup source with less water quality.

Managerial and regulatory impacts were also frequent themes across interviews. Managerial impacts were felt more strongly by S3 managers (71\%) than non-S3 managers (57\%), and included the need to implement increased tracking and reporting and training or hiring staff to help meet the state's conservation requirements. S3 managers also frequently reported the paradox of pushing their customers to decrease water purchasing while at the same time needing increased purchases to raise the capital for necessary system improvements. Illustrating the hardships experienced, one S3 manager explained,

"It [the Drought] screwed us up so bad... When the Drought mandates came down from the governor, it didn't affect the golf courses or the farms, it was just the people. And they're screaming- why are you getting $25 \%$ of the savings from $10 \%$ of the problem? You need to go after the others...We set-up a conservation program. We didn't have money for rebates, but we did some ordinances, so we could impose pen- 
alties, but the board was very reluctant about imposing penalties on people for that very reason-- when they're watching the golf course across the street overwatering onto the street, and they're not supposed to water anymore. It was very difficult for us." (S3 system manager)

In comparison to managerial impacts, regulatory impacts were more commonly reported by non-S3 managers (64\%) than S3 system managers (54\%), but across both S3 and nonS3 managers, the state Conservation Mandate was discussed extensively. S3 managers reported that the "one size fits all" approach simply does not work and that asking systems to achieve compliance in a short turn-around regardless of system size and capacity is setting small systems up for failure. While feedback was overwhelmingly negative about the conservation mandate, several managers (a mix of S3 and non-S3 managers) noted that the Conservation Mandate was helpful because it gave them leverage to push consumer attitudes and behaviors toward greater water conservation.

\subsection{Drought responses}

Responses to the Drought ranged from efforts to short-term, emergency demand management strategies focused on residential conservation to more permanent, internal institutional changes within water system management. In interviews, both S3 and non-S3 managers reported similar categories of Drought responses (i.e., demand management, technical strategies, source extension, and partnerships), though the specific responses within these categories varied (Fig. 4). In regional workshops, S3 managers shared Drought responses consistent with interview findings, such as the emphasis on consumer outreach and incentive programs to decrease demand, efforts to restructure water rates, adopting additional treatment technologies, and building more strategic relationships between water systems and other local agencies to pursue regional solutions. At each workshop and in the Policy Forum, participants noted that building partnerships, collaborations, and more broadly, relationships among water systems and regional stakeholders emerged at least in part

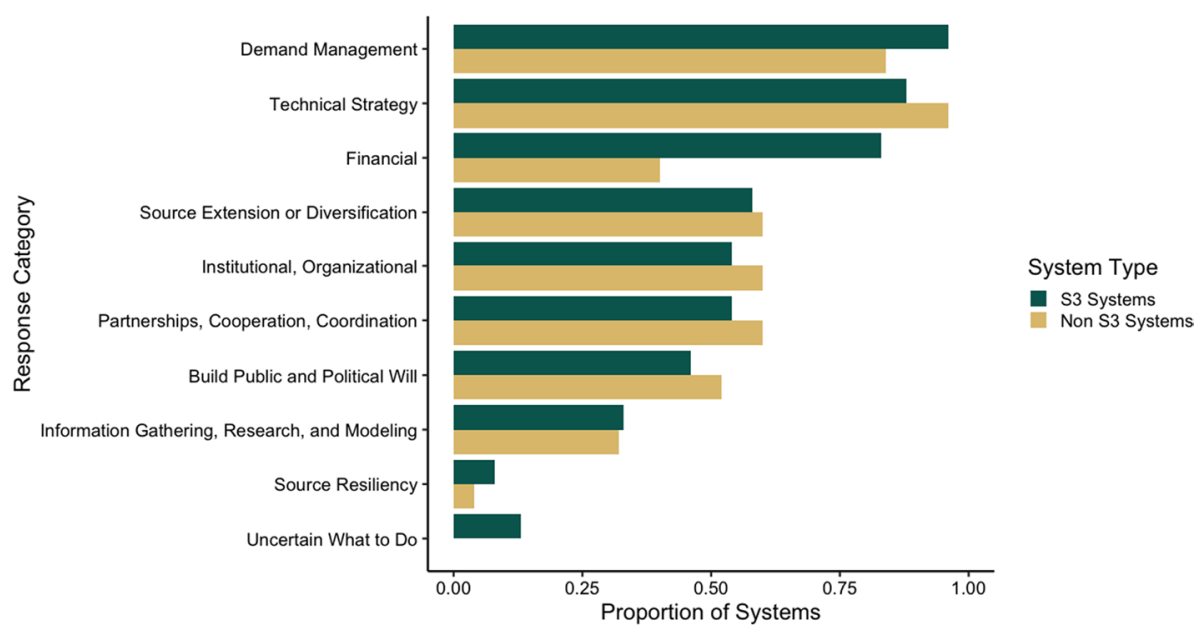

Fig. 4 Drought response categories by system type (categories were inductively developed and are defined in Online Resource 4) 
because of the severity of the Drought and the need to collectively combat its impacts over the long-term.

Financial responses were described by a much higher proportion of S3 managers (83\%) than non-S3 managers (44\%), likely due to the number of emergency financial program opportunities targeting smaller and disadvantaged systems that the state offered during the Drought. S3 system managers often mentioned the importance of accessing local, state, and federal grants and loans to implement technical or source extension/diversification strategies. In several interviews, managers pointed to funding provided by their wholesaler: "[...] they're like our big brother. They are very open to supplying seed money for these grants, which is nice." When relationships were strong, like this one, S3 managers described turning to wholesalers for advice and technical assistance. Other financial responses adopted included pursuing rate-related changes such as conservation/drought surcharges and external financial assistance. Among S3 manager responses, some reported undergoing a Prop 218 rate adjustment process ${ }^{4}$ to raise rates and incentivize conservation. In a few instances, rate adjustment processes were successful because of the Drought—one S3 manager credited the Drought's severity with enabling them to adopt a tiered rate structure without customer pushback.

In response to the Drought and facilitated by the 2015 Conservation Mandate (Mandate), both S3 and non-S3 managers reported local conservation messaging efforts. S3 managers discussed building public and political will for conservation, alongside demand management strategies, and the importance of presenting cohesive messaging to consumers with neighboring water systems. Many S3 managers credited the state's Save Our Water campaign and the Mandate with providing higher-level messaging that they pointed to when customers were confused or pushed back on reducing use. A handful of managers expressed their added frustration of having to comply with the statewide conservation requirements, either because they already had sufficient demand management strategies or because they were frustrated with the Mandate's implementation. Many shared the sentiment that the small amount of saved water through residential restrictions was unlikely to mitigate the Drought impacts in their groundwater basin, especially when competing with large, agricultural pumpers. Furthermore, low-resourced systems without in-house staffing devoted to conservation programs meant they felt an additional burden of the Mandate's compliance and reporting requirements on top of the ongoing challenge of managing during the Drought.

\subsection{Drought barriers}

Barriers to drought adaptation and resilience ranged from frustration with state or local politics to financial need to physical and infrastructure-related challenges. Like patterns found in examining the Drought impacts and responses, interviewed S3 and non-S3 managers mentioned similar top drought barrier categories (regulatory, communication, physical, and resource), but the specific barriers discussed varied across the two groups (Fig. 5). A high proportion of S3 (86\%) and non-S3 (76\%) managers mentioned the Mandate as a regulatory barrier, however S3 managers noted it failed to consider the needs of smaller

\footnotetext{
${ }^{4}$ Proposition 218 passed and was adopted as a California constitutional amendment in 1996. This amendment requires that all tax increases and most charges to property owners are subject to voter approval. Increases in certain water supplier rates are subject to this approval.
} 


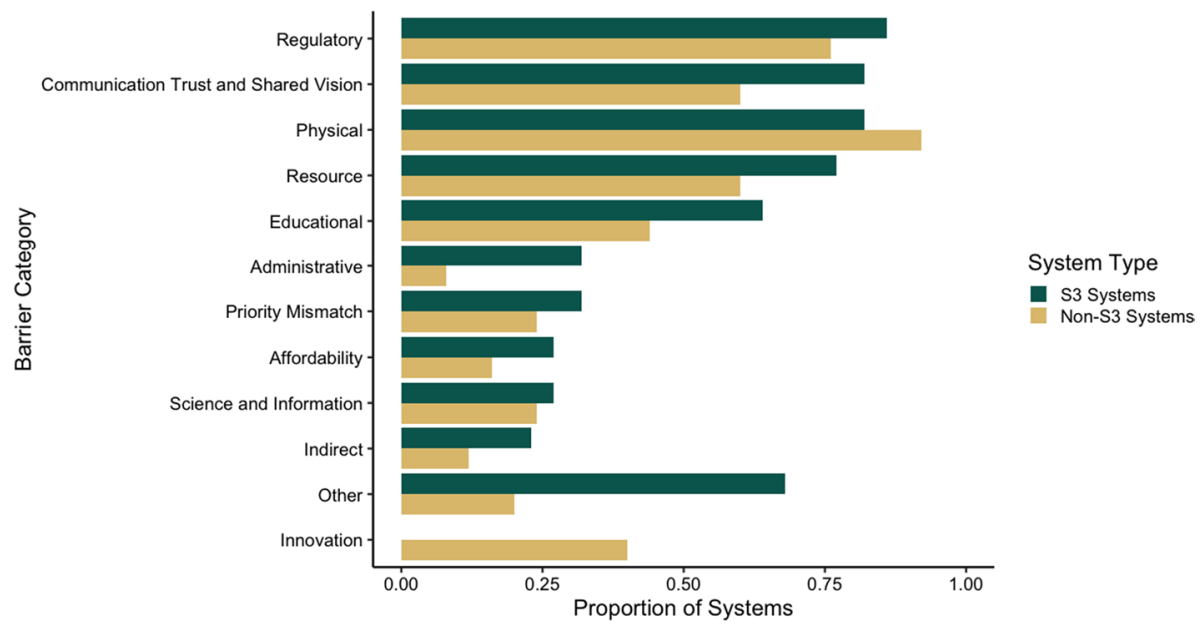

Fig. 5 Drought barrier categories by system type (categories were inductively developed and are defined in Online Resource 4)

systems (at the time of interviews), while non-S3 managers reported that the Mandate prevented them from supplying water to their customers. Frustration with state determinations of "drought-induced" water quality issues and definitions of "disadvantaged community" were other commonly reported barriers by S3 managers. These narrow definitions often precluded S3 managers from accessing much-needed funding.

Internal politics and geography also play a role in preventing system managers from addressing the Drought. In fact, $82 \%$ of S3 managers reported some type of communication, trust, or shared vision barrier, such as frustration with board members or other watershed stakeholders failing to acknowledge climate change and the importance of long-term planning. Similarly, $82 \%$ of S3 managers reported physical barriers to drought planning. Within this barrier category, several managers noted wasted time and money spent by previous system board members on calculating consolidation costs, which were ultimately deemed to be too significant because of the geographic remoteness of the system. Where consolidation was unlikely because of geographic barriers, managers voiced concern over water availability and aging infrastructure. In situations where consolidation or other approaches were possible, inaction, whether on the part of the board, the community, or the state, became a key driver in (not) shaping drought response and planning.

A common theme that emerged from interviewee experiences was the overlapping and intertwined nature of the barriers. This was especially apparent within the resourcerelated barriers (e.g., technical, managerial, or financial capacity) category. For example, S3 managers discussed a lack of staff capacity (resource barrier) to develop protocols in response to the Mandate requirements (regulatory barrier). These same managers lacked financial capacity (resource barrier) to address aging infrastructure (physical barrier) and were unable to apply for certain funding programs due to limited staff capacity (resource barrier) or ineligibility based on narrow state definitions (regulatory barrier). As one S3 manager explained, “... bigger systems seem to have [an] easier time responding to quick regulatory challenges... they have staff devoted to conservation efforts [even when there is not a drought]." The inherent overlap of barriers was discussed at the Policy Forum, though without much progress toward resolution. Forum attendees noted the challenge of 


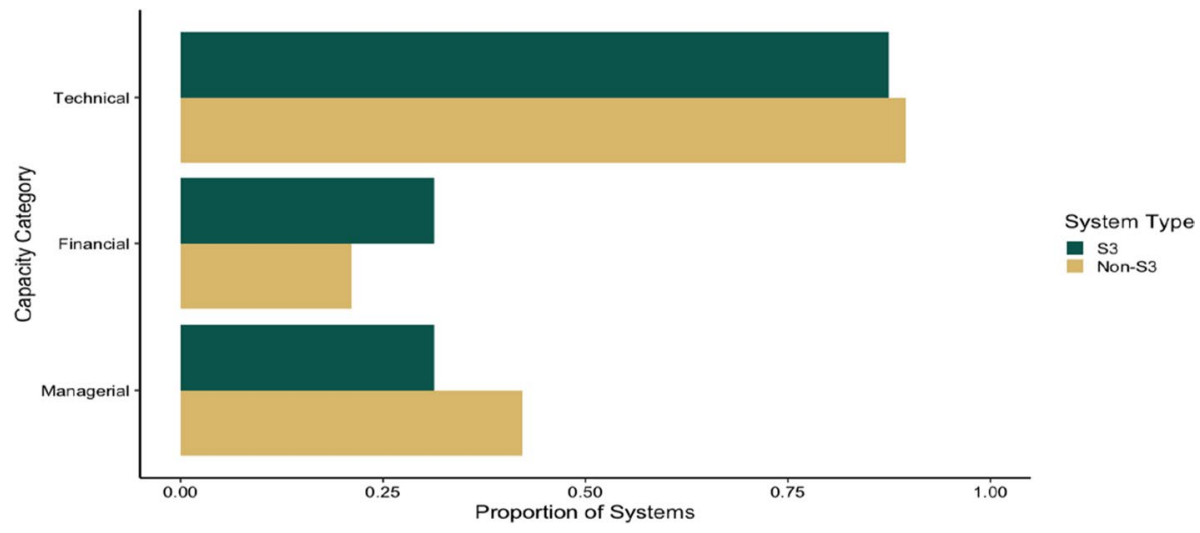

Fig. 6 Drought adaptive capacity categories by system type (categories were inductively developed and definitions align with U.S. EPA 2021 drinking water TMF definitions)

identifying and developing effective policy responses that can account for multi-faceted barriers.

\subsection{Solutions and climate change adaptation}

This section presents an overview of investments in adaptive capacity made by system managers prior to the Drought. Strategies were grouped by technical, managerial, and financial capacities. We also report future strategies for building drought resilience and climate adaptation, as discussed by the system managers. Many of these latter results were discussed in regional workshops and at the Policy Forum.

\subsubsection{Invest in adaptive capacity before drought}

Overall, fewer S3 managers $(58 \%, 14)$ than non-S3 managers $(76 \%, 19)$ mentioned some type of adaptive capacity in place prior to the Drought. Most systems in our study set (35/49) had some level of adaptive capacity preceding the Drought (Fig. 6), though the level varies across S3 and non-S3 systems. Capacities include technical strategies like sufficient backup supplies, water meters that facilitate conservation behaviors and supply augmentation approaches like groundwater recharge programs, recycling, and using treated wastewater, as well as the presence of existing interties with nearby systems for supply flexibility. Managerial capacities include proactive education and outreach programs, and the existence of water-sharing agreements or drought-related rules and management strategies. The final set of capacities includes financial strategies like having an appropriate (often tiered) rate structure, or a rebate or conservation incentive program.

S3 managers generally discussed less expensive and less technologically advanced actions than non-S3 managers (e.g., non-S3 managers offered recycled water programs, financial planning for droughts, and others). Managers often discussed how actions taken prior to the Drought put them in a better situation than if they had not acted, pointing to the system's ability to build drought resilience in between drought events. 


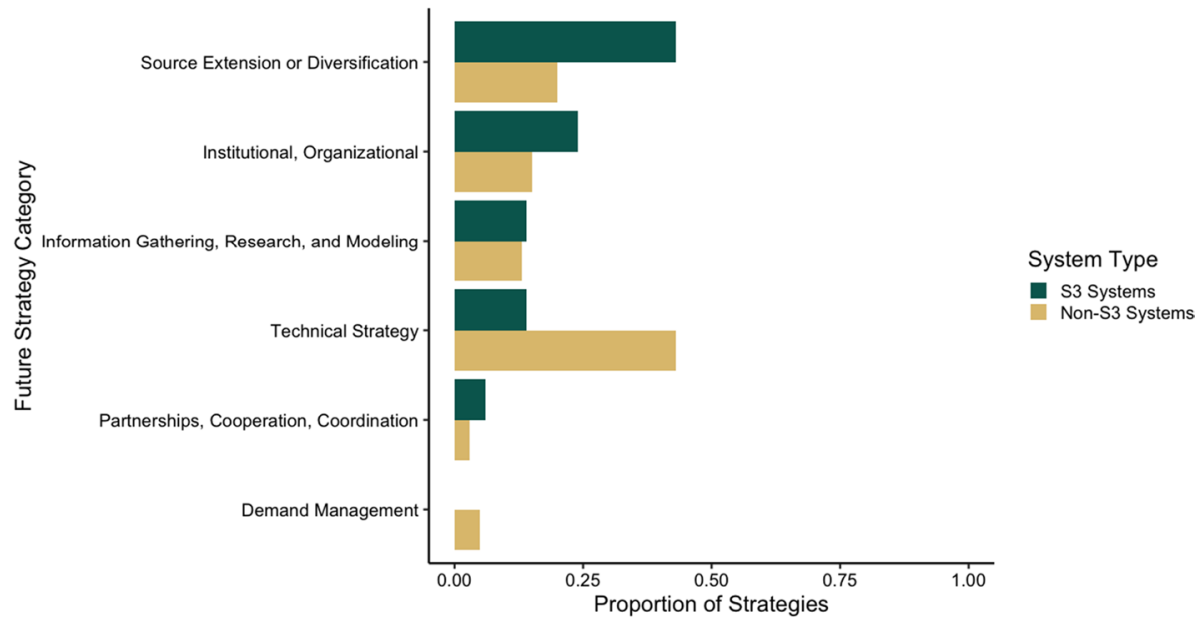

Fig. 7 Future drought strategies discussed by system type (categories were inductively developed and align with drought response categories in Fig. 4. See Online Resource 4 for definitions)

\subsubsection{Future strategies for building drought resilience}

More than half of the system managers interviewed identified a strategy that could help them to be better prepared for current and future droughts but that they had not yet implemented. A higher proportion of S3 managers (79\%) than non-S3 managers $(60 \%)$ identified such strategies. The most common type of future strategy mentioned by S3 managers was extending or diversifying their water sources, strategies that many small systems struggle to self-finance without emergency financial relief (such as what became available during the Drought). Study participants, across all three data collection stages, communicated how important it is to be able to invest in the types of strategies to prepare for and mitigate against future drought impacts (Fig. 7).

\subsubsection{Pursuing climate adaptation and drought resilience}

Except for a small number of participating systems, most managers expressed that they were not actively involved in climate adaptation. However, when applying the broad definition of climate adaptation we introduce in the framing of the adaptation section, 34 of the 49 interviewees (14 S3 managers and 20 non-S3 managers), discussed at least one climate change adaptation strategy. Adaptation strategies identified in interview transcripts were naturally grouped into seven nonexclusive categories and were largely related to building long-term drought resilience (Fig. 8).

The top climate adaptation strategy types shared by system managers were source extension and source resiliency, consistent with the emphasis on future drought strategies. Eighty percent of non-S3 managers described efforts to extend or diversify sources, compared to $64 \%$ of the S3 managers. The largest difference in climate adaptation strategies described by S3 and non-S3 managers was that institutional or organizational-related approaches to adaptation were emphasized by a higher proportion of non-S3 than S3 managers. 


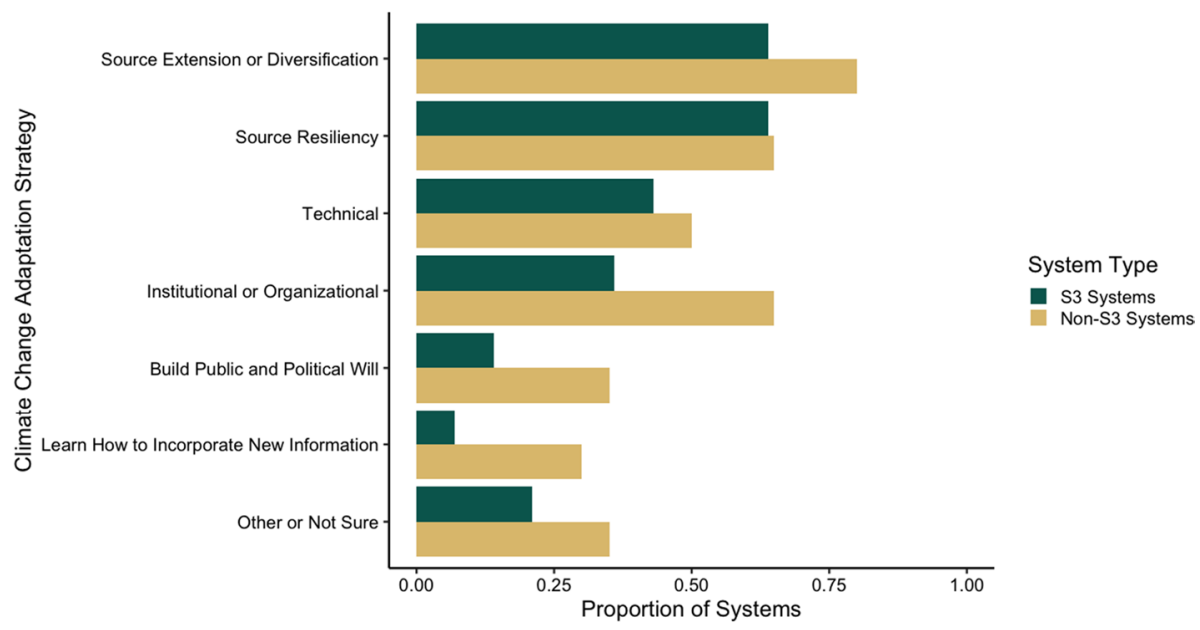

Fig. 8 Climate change adaptation strategies by system type (categories were inductively developed and align with Drought response categories in Fig. 4; incorporating new information was adapted from Moser and Ekstrom 2010)

The Policy Forum offered a larger focus on climate adaptation and the long-term needs of small water systems. Attendees communicated that collaboration is an essential component of any effort aimed at reducing small system barriers to drought and climate resilience. Tribal representatives and policymakers involved in tribal water management placed emphasis on collaboration as a key to integrating the unique needs of tribal water organizations. Attendees shared enthusiasm for, and the potential capabilities of, the Sustainable Groundwater Management Act (SGMA) to address several small system barriers, including physical and communication, trust, and shared vision in addition to the benefit of regional groundwater management solutions for drought resilience. Since its implementation, however, some question its success on these fronts (Dobbin 2020; Méndez-Barrientos et al. 2020; Dobbin and Lubell 2019). Partly in response to this questioning, the Governor's State of Emergency Proclamation (Newsom 2021) called for the two state water agencies to develop principles for drought impacts response and proactive planning for communities reliant on groundwater. In reflection of existing and proposed regulatory efforts, Policy Forum attendees generally agreed that existing policies look good on paper but identified two flaws: (1) they target and are often developed with larger systems in mind, and (2) they are often unfunded, potentially creating an additional burden on smaller systems. Discussants also generally agreed that, in their experience, small systems find it difficult to meet new regulations, in part due to a lack of an implementation grace period. Relating back to an earlier point on barriers as overlapping challenges, when regulations outline an expectation that all systems meet requirements on the same timeline, small systems tend to experience a domino effect of burden; not only do they fail to meet the implementation deadline, but they may also face staff capacity challenges, supply availability concerns, financial hardships, and more. This is consistent with findings from Moser et al. (2018) on barriers to funding adaptation among local governments, which found that governments need to overcome bundles of barriers simultaneously to advance adaptation. 
On the topic of solutions to overcome small system barriers, Policy Forum attendees spent much of the small group breakout time discussing potential models of local drought assistance. For example, participants discussed the East Porterville project, a multi-year effort which funneled millions of dollars into an unincorporated community that was considered "ground zero" for the Drought; hundreds of homes are reliant on domestic wells that ran dry (DWR 2018). This effort pulled together a multitude of stakeholders to first provide bottled water and temporary water storage tanks to households with dried domestic wells. Ultimately, state agencies and others facilitated physical service connections between these homes and the City of Porterville system. Despite its eventual success, Policy Forum attendees noted it may not be a feasible solution to apply statewide because of the high financial and time investment. Although not a small system example, East Porterville serves as a useful demonstration of what is possible with state investment in local and regional drought strategies and how flexibility and creativity can help build trust where it is needed.

Policy Forum attendees agreed that policy efforts and campaigns should consider incorporating performance measures to ascertain each effort's effectiveness in helping small system managers overcome barriers to drought and climate resilience. Attendees agreed that the conversation around drought, drinking water, and small systems needs to be continued despite Governor Brown's declaring the Drought over for the majority of California in early 2017. Since 2017, the state pursued several programs to address the challenges discussed by system managers, most notably the 2019 passing of SB200, which created the Safe and Affordable Drinking Water Fund. As of June 2021, 85\% of California is in extreme drought, and Governor Newsom declared a drought emergency in 41 of California's 58 counties. This new drought will test how well the state responded to the previous challenges.

\section{Discussion}

We set out to inventory the Drought experiences of small, self-sufficient system managers with the intention of providing insights into ongoing efforts and needs for climate adaptation. We found that, based on the systems studied in this project, small, self-sufficient water systems have different drought experiences and needs compared to larger systems. As in most complex natural resource management issues, "the devil is in the detail." Here we explain the cross-cutting themes that arose from our study: (1) water supply resiliency and robustness; (2) funding mechanisms; (3) communication; and (4) social equity (see Online Resource 5 for a summarized visual depiction).

\subsection{Water supply resiliency and robustness}

The critical role of a resilient and/or robust supply portfolio was discussed frequently throughout this project. Systems can become more drought prepared by expanding storage capacity, upgrading distribution system components and water treatment facilities, replacing wellheads, drilling wells deeper, or forest preservation in a source's watershed. These strategies are pursued to protect existing supplies or add supply portfolio redundancy and diversity. S3 managers also mentioned supply diversification and source redundancy 
as future strategies necessary for drought resilience that require additional support to implement.

Because of the investments made prior to the Drought, many non-S3 systems were more physically and administratively prepared for the Drought. Additionally, many non-S3 systems must file Urban Water Management Plans (UWMPs) with the state every 5 years. As a result, many non-S3 systems already had existing Water Shortage Contingency Plans that outlined multiple dry year scenarios. For these systems, the existence of such plans, combined with the ability to enact the plan as needed, stood in contrast to the lack of drought adaptive capacity reported by S3 systems. In general, large non-S3 systems have the technical, managerial, and financial capacity to invest in strategies that positively influence long-term drought resilience. Comparatively, small systems are not required to file an UWMP and often have lower capacity to expand sources or diversify portfolios. The Drought pushed the state to shift existing planning requirements. For example, SB 552, requires new drought contingency plans by 2023. To be successful, SB 552 will need funding support.

State legislation and policies written since the Drought lay out a series of proposals to help facilitate regional supply diversification and drought preparedness. AB 1668 and SB 606 (2018) work to strengthen long-term water conservation and drought planning among large urban suppliers and specifically include provisions to identify vulnerable small and rural water systems and to provide the legislature with drought planning recommendations. The 2018 legislation and policy set good foundations-which the SB552 now codifies into state law-for future small system drought and climate preparedness. We caution, however, that diversifying source waters and making other drought preparations often rely on access to external funding sources. Those funding sources need to be available in a way that managers can proactively prepare their systems and invest in necessary adaptive capacity. Any state legal requirements should be done so in conjunction with funding opportunities and capacity assistance programs specifically designed to help alleviate the burden on small systems. With this in mind, we next turn to a discussion of funding mechanisms for small systems.

\subsection{Funding mechanisms for small systems}

Financial resources and constraints were key components of impacts, responses, and barriers expressed by system managers. Funding and financing were described as necessary for improving supply portfolios and to support responding to other challenges posed by the Drought. For example, small system managers discussed the need to balance consumer affordability with the need to restructure rates. In several cases rates remained stagnant for years and even decades; as a result, systems were unable to generate revenue to keep pace with operation and maintenance needs. This is a persistent problem in California, and the consequence of under-investment in an aging infrastructure leads to failing systems with water reliability and distribution problems during the Drought. In comparison, several system managers reported that revising rate structures prior to the Drought became an adaptive capacity strategy that reduced impacts. Updating rate structures can be an expensive, lengthy, and politically contentious process that can ultimately require two-thirds public approval (via Proposition 218 of the California Constitution, 1996). This legal financing challenge makes it more difficult to update rate structures in a way that helps systems dynamically prepare for drought in the long term as well as climate adaptation. 
To assist drinking water systems (particularly smaller systems serving disadvantaged communities), the state offered several funding packages and other processes during the drought to provide emergency assistance and help facilitate the restructuring of rate systems. These included the emergency drought funding made available to water systems from Prop 84 (Safe Drinking Water Bond Act of 2006), AB 92 (Committee on the Budget. Water, 2015), and AB 93 (Budget Act of 2015) and created the Office of Sustainable Water Solutions to promote permanent and sustainable drinking water solutions. This money was crucial to assisting drinking water systems overcome challenges during the Drought, yet several S3 managers discussed the onerous process of applying for funding, which discouraged them from applying in some cases. As constraints were recognized, the state introduced some flexibility, including verbal agreements to initiate funded projects. Future funding mechanisms should be designed in a flexible way that reflects the needs and challenges voiced by small system managers. Furthermore, funding should be made available before climate emergencies arise so that managers can prepare their systems. After the Drought, the legislature passed a landmark funding program, which created an ongoing, sustained funding source to support systems. The program, called the Safe and Affordable Drinking Water Fund (SB 200, 2019), requires up to $\$ 130$ million per year to be transferred through 2030 from the state's Cap and Trade program (SWRCB 2021). The SAFER (Safe and Affordable Funding for Equity and Resilience) program, set up to administer the Fund, is designed to "bring true environmental justice to California" and achieve the Human Right to Water (SWRCB 2021).

Many barriers and responses lie outside managers' immediate decision-making space and may require regional and state-level engagement for long-term solutions. For example, another topic of frustration discussed in workshops and interviews was the use of median household income (MHI) as a measure for determining "disadvantaged community" (DAC) status. ${ }^{5}$ Managers argued that using MHI as a measure for the water sector is challenging because proving DAC status when census data are inaccurate requires costly household surveys. Establishing an easier process to prove their customers meet a low income or another criterion of marginalization could enable systems to be eligible for a wider range of funding opportunities.

\subsection{Communication}

A third cross-cutting theme arising from the study was communication; this includes communication between system managers and consumers, between multiple water systems, between the State and water systems, and between system managers and other water users (agricultural uses, recreational, conservation, etc.). Communication is a critical tool that managers use to reduce demand and encourage conservation behaviors among consumers. Communication from the State to California supported and helped to reinforce local conservation efforts. Several S3 managers appreciated and made use of the consistent Save Our Water campaign message when working to change their customers' water usage or in communicating the Drought's local severity. Communication among and between systems and nearby water users was useful for building trust, sharing information and advice,

\footnotetext{
${ }^{5}$ In California, a disadvantaged community (DAC) is a census unit (tract, block, or place) that has an annual median household income (MHI) that is less than $80 \%$ of the statewide annual MHI (CA Water Code $\$ 179505.5 a)$.
} 
developing water-sharing agreements, and in some instances, effectively coordinating county-level Drought responses.

Most communication barriers facing S3 managers are related to local politics and stakeholders with multiple and often opposing priorities. These challenges often relate to trust: building it and maintaining it as a prerequisite for effective communication. Like previous water challenges in California, tensions between agricultural and drinking water stakeholders were raised by several managers. A common perspective expressed was that agriculture uses much of the water, so why would not agricultural users be held to the same (or stricter) conservation requirements as drinking water systems? Conflicting views on climate change by both managers and among consumers and other water users in the community were commonly discussed communication barriers. Outreach campaigns can be a means to bring drinking water system managers and consumers together by educating community members on the value of water and the process of getting water from the source to the tap. Future efforts from the state to provide consistent and transparent messaging before, during, and after the drought may play especially important roles as drinking water managers navigate between raising capital for necessary infrastructure improvements and promoting water conservation. Building trust and communication will be especially important as managers work to prepare their systems to be climate resilient.

\subsection{Social equity}

Social (in)equity was perhaps the most pervasive theme that emerged from discussions with drinking water managers. Many small drinking water systems are part of a long history of environmental and social inequity in California (London et al. 2021, 2011; Christian-Smith et al. 2013; Balazs et al. 2012). This drinking water inequity is exemplified by selective enforcement of water regulations (Balazs et al. 2012), lack of community political power (Francis and Firestone 2010), historical redlining processes (Marsh et al. 2010), and inequitable funding access (Imperial 1999). As a result of these inequities, many, often smaller, communities face poorer water quality, unreliable accessibility, and increased health disparities (Balazs et al. 2021, 2012, 2011).

Through our study, we found local managers differ in their ability to adapt. Water systems serving marginalized populations tended to have fewer resources to plan for climate change impacts. Given the likelihood that California will experience more frequent and intense droughts in the future (Diffenbaugh et al. 2015), struggling systems will continue to be left behind in the absence of focused and intentional change. For example, during the Drought, water quality concerns like harmful algal blooms emerged in our research as a challenge for drinking water management that currently lacks federal and state regulatory standards (CWQMC 2021). Looking forward, combinations of extreme events, such as drought and wildfire are likely to further complicate drinking water management approaches, challenges, and solutions. Several drinking water managers are already facing these issues, as one interviewee noted that they told the fire department, “... if there's a fire, just let it burn down. It's cheaper to rebuild than deal with that...". Throughout our data collection phase, study participants expressed that existing and emerging challenges are compounded by a lack of political voice to advocate for necessary changes. Advancing equitable social adaptation can necessitate additional assistance from higher institutional 
levels outside the local water system given the potential limits to independent adaptation among small systems (Garrick et al. 2018; Shi et al. 2016).

\subsection{Looking toward the future}

Looking toward the future, we can garner insights in using the Drought to signify climate change and inform adaptation by water managers. Our research shows that approaches to, and capacities for, climate adaptation vary across system types. This variation was exemplified in assessing involvement in the climate adaptation process; more non-S3 managers engage in institutional or organizational-related approaches than S3 system managers. Making organizational changes is a social form of adaptation that indicates a deeper and long-lasting change supporting the adaptation processes over the long term (Measham et al. 2011; Næss et al. 2005). Organizational changes implemented by non-S3 managers prior to and during the Drought, such as participating in regional recycled water programs and long-term financial planning for drought by adopting modified rate structures, are examples of actions that could help S3 managers. Participating in and pursuing regional solutions for drought (and climate) resilience often in partnership with larger systems offer an important way for small systems to diversify supply portfolios, have climate-resilient supplies, and leverage state investments to achieve social equity goals.

\section{Conclusion}

This study employed a multiple method approach to gather insights and triangulate experiences from drinking water managers, specifically those from small, self-sufficient systems. The strengths of this research design, compared to previous efforts, include statewide geographic coverage and a high diversity among system types. A key contribution of the study is its inclusion of and reliance on local expertise, particularly by gathering and documenting in-depth manager drought experiences from an understudied group of water systems. By triangulating our findings and sharing and verifying them iteratively with water managers throughout the project we increased the transparency and reliability of our results. The main limitation of this approach was the time demand and duration between interviews in summer 2016 and the Policy Forum in summer 2017.

To reiterate, the partnership between the University of California-Davis and the Environmental Justice Coalition for Water was essential for ensuring that workshops and Policy Forum structures provided a space for local stakeholders and state-level decision makers to be in conversation about drought impacts and barriers in pursuit of lessons learned as the Drought dissipated in intensity. Ultimately, spending more time on each stage of the iterative approach helped us achieve our objective to better understand and document the experiences of small, self-sufficient drinking water managers during the Drought.

California often looks outside its borders to places like Israel, Australia, and other high-income and drought-prone countries with Mediterranean climates for insight and innovation on responding to extreme events. These countries can learn from the different adaptation pathways undertaken by California's small and self-sufficient water systems. Our findings suggest that small systems face different impacts and barriers to drought (compared to larger systems), that influence how they decide to respond. As such, rather than assuming that the path to resilience is downscaling or retrofitting large 
system responses and approaches to smaller systems, decision-makers should support small systems learning from one another. While the complexity of California's multilevel governance and highly engineered system challenges may not be as generalizable to other high-income countries, the level of decentralization could offer lessons learned for other arid and semi-arid places in the US, especially among rural communities that rely on self-supplied (not imported) drinking water.

There is no resource more vital to a society's health and wellbeing than clean, affordable, and accessible drinking water. Situated in a semi-arid climate, California has a highly diverse and complex system of water governance. Our findings underscore that this complicated set of governance systems, across levels and geography, explains why climate adaptation is not yet happening everywhere. In California, safe drinking water is a human right. Building on the state's current progress in supporting the water sector in adaptation efforts, this study provides insight into how to support small, self-sufficient systems to prepare for climate change and future droughts. Strategies that transform and better define the roles, accountability, and responsibilities to adapt could make the changes necessary to prepare small systems and their customers for climate change while working toward achieving the promised human right. The Drought impacts different managers reported are not new nor are the multitude of ways in which water systems throughout the state adapt to drought. However, these pervasive challenges must be addressed if California is to realize effective drinking water adaptation across the state. Only through continuing to listen to and gather local drinking water managers' collective expertise, can the state understand whether existing policy efforts are accomplishing what they set out to do or whether new policies and programs are needed to build a climate-resilient water system.

Supplementary Information The online version contains supplementary material available at https://doi. org/10.1007/s 10584-021-03305-8.

Acknowledgements This work was supported by the California Natural Resources Agency [California Fourth Climate Change Assessment]. In addition, M. Klasic and J. Ekstrom's time on this project was partially supported by USEPA grant number 83519401 and A. Fencl's time was partially supported by the National Science Foundation Graduate Research Fellowship program. All opinions expressed are those of the authors and do not represent the views of their affiliated institutions nor their funders, including the State of California, the University of California, Davis, the USEPA, and NSF.

We appreciate the California State Water Resource Control Board, Department of Water Resources, and Indian Health Services, as well as numerous study participants for contributing their data and insights about water systems during the study. We thank Dr. Mark Lubell, Dr. Zeke Baker, and Frances Einertz for contributing to the Fourth Climate Change Assessment project implementation. Lastly, we thank the anonymous reviewers for their suggestions.

Open Access This article is licensed under a Creative Commons Attribution 4.0 International License, which permits use, sharing, adaptation, distribution and reproduction in any medium or format, as long as you give appropriate credit to the original author(s) and the source, provide a link to the Creative Commons licence, and indicate if changes were made. The images or other third party material in this article are included in the article's Creative Commons licence, unless indicated otherwise in a credit line to the material. If material is not included in the article's Creative Commons licence and your intended use is not permitted by statutory regulation or exceeds the permitted use, you will need to obtain permission directly from the copyright holder. To view a copy of this licence, visit http://creativecommons.org/licenses/by/4.0/. 


\section{References}

Archie KM, Dilling L, Milford JB, Pampel FC (2014) Unpacking the "information barrier": comparing perspectives on information as a barrier to climate change adaptation in the interior mountain West. J Environ Manage 133:397-410. https://doi.org/10.1016/j.jenvman.2013.12.015

Ayeb-Karlsson S, van der Geest K, Ahmed I, Huq S, Warner K (2016) A people-centered perspective on climate change, environmental stress, and livelihood resilience in Bangladesh. Sustain Sci 11:679-694. https://doi.org/10.1007/s11625-016-0379-z

Baker Z, Ekstrom JA, Bedsworth L (2018) Climate Information? Embedding Climate Futures within Temporalities of California Water Management. Environmental Sociology 4(4):419-433. https://doi.org/ 10.1080/23251042.2018.1455123

Balazs CL, Morello-Frosch R, Hubbard AE, Isha R (2011) Social disparities in nitrate-contaminated drinking water in California's San Joaquin valley. Environ Health Perspectives 119:1272-1278. https://doi. org/10.1289/ehp.1002878

Balazs CL, Morello-Frosch R, Hubbard AE, Ray I (2012) Environmental justice implications of arsenic contamination in California's San Joaquin Valley: a cross-sectional, cluster-design examining exposure and compliance in community drinking water systems. Environ Health 11:84. https://doi.org/10.1186/ 1476-069X-11-84

Balazs CL, Goddard JJ, Bangia KM, Wieland W, Faust, JB (2021) Achieving the human right to water in California: an assessment of the state's community water systems. California Office of Environmental Health Hazard Assessment. https://oehha.ca.gov/media/downloads/water/report/hr2wframeworkpu blicreviewdraft010319.pdf

Berg N, Hall A (2015) Increased interannual precipitation extremes over California under climate change. J Climate 28:6324-6334. https://doi.org/10.1175/JCLI-D-14-00624.1

Bostic D (2021) At risk: public supply well vulnerability under California's sustainable groundwater management act. Pacific Institute, Oakland, California

Brown EG (2014) Executive order B-17-14. Signed January 17, 2014. https://www.ca.gov/archive/gov39/ 2014/01/17/news18368/

Brown EG (2015) Executive order B-29-2015. Signed April 1, 2015. https://www.ca.gov/archive/gov39/ wp-content/uploads/2017/09/4.1.15_Executive_Order.pdf

California Senate (2021) SB-552 drought planning: small water suppliers: nontransient noncommunity water systems, https://leginfo.legislature.ca.gov/faces/billNavClient.xhtml?bill_id=202120220SB552

California State Water Code $\$ 79505.5$ (2002) https://leginfo.legislature.ca.gov/faces/codes_displaySection. xhtml?lawCode $=$ WAT\&sectionNum $=79505.5$

Christian-Smith J, Levy MC, Gleick PH (2015) Maladaptation to drought: a case report from California, USA. Sustain Sci 10:491-501

Christian-Smith J, Balazs CL, Heberger M, Longley K (2013) Assessing water affordability: a pilot study in two regions of California. Pacific Institute, Oakland, California

Conrad E (2013) Preparing for new risk: addressing climate change in California's urban water management plans. University of California, Berkeley, Berkeley, California

Cornwall A (2008) Unpacking 'participation': models, meanings and practices. Community Development J 43:269-283. https://doi.org/10.1093/cdj/bsn010

Costanza R, Graumlich L, Steffen W et al (2007) Sustainability or collapse: what can we learn from integrating the history of humans and the rest of nature? Ambio 36:522-527

CWQMC (2021) My water quality: California harmful algal blooms (HABs). California Water Quality Monitoring Council. https://mywaterquality.ca.gov/habs/what/index.html. Accessed 22 Jul 2021

Dettinger MD (2011) Climate change, atmospheric rivers, and floods in California - a multimodel analysis of storm frequency and magnitude changes. Journal of the American Water Resources Association 47:514-523. https://doi.org/10.1111/j.1752-1688.2011.00546.x

Dettinger MD (2013) Atmospheric rivers as drought busters on the U.S. West Coast J Hydrometeorology 14:1721-1732. https://doi.org/10.1175/JHM-D-13-02.1

Diffenbaugh NS, Swain DL, Touma D (2015) Anthropogenic warming has increased drought risk in California. PNAS 112:3931-3936. https://doi.org/10.1073/pnas.1422385112

Dilling L, Daly ME, Travis WR et al (2015) The dynamics of vulnerability: why adapting to climate variability will not always prepare us for climate change. Wiley Interdiscip Rev Clim Change 6:413-425. https://doi.org/10.1002/wcc.341

Dilling L, Pizzi E, Berggren J, Ravikumar A, Andersson K (2017) Drivers of adaptation: responses to weather- and climate-related hazards in 60 local governments in the Intermountain Western U.S. Environ Plan A 49:2628-2648. https://doi.org/10.1177/0308518X16688686 
Dilling L, Daly ME, Kenney DA et al (2019) Drought in urban water systems: learning lessons for climate adaptive capacity. Clim Risk Manag 23:32-42. https://doi.org/10.1016/j.crm.2018.11.001

Dobbin KB (2020) "Good luck fixing the problem": small low-income community participation in collaborative groundwater governance and implications for drinking water source protection. Society \& Natr Resources 33(12): 1468-1485 https://doi.org/10.1080/08941920.2020.1772925

Dobbin KB, Fencl AL (2021) Institutional diversity and safe drinking water provision in the United States. Utilities Policy. https://doi.org/10.1016/j.jup.2021.101306

Dobbin KB, Lubell M (2019) Collaborative governance and environmental justice: disadvantaged community representation in California sustainable groundwater management. Policy Studies J 49(2):62-90

DWR (2021a) State Water Project. California Department of Water Resources, Sacramento, CA. https:// water.ca.gov/Programs/State-Water-Project

DWR (2021b) Drought Funding. California Department of Water Resources, Sacramento, CA. https://water. ca.gov/Water-Basics/Drought/Drought-Funding

DWR (2018) East Porterville Water Supply Project Connects 755 Homes. California Department of Water Resources. Sacramento, CA. https://water.ca.gov/News/News-Releases/2018/Feb-18/East-PortervilleWater-Supply-Project-Connects-755-Homes

DWR (2014) Public Update for Drought Response: Groundwater Basins with Potential Water Shortages, Gaps in Groundwater Monitoring, Monitoring of Land Subsidence, and Agricultural Land Fallowing. California Department of Water Resources. Sacramento, CA

DWR (2011) 2010 Urban Water Management Plans Guidebook. California Department of Water Resources. Sacramento, CA

DWR (2010) California Drought Contingeny Plan. California Department of Water Resources. Sacramento, CA

DWR (2008) Managing an uncertain future: climate change adaptation strategies for California's water. California Department of Water Resources. Sacramento, CA

Ekstrom JA, Moser, (2014) Identifying and overcoming barriers in urban climate adaptation: Case study findings from the San Francisco Bay Area, California, USA. Urban Climate 9:54-74. https://doi. org/10.1016/j.uclim.2014.06.002

Ekstrom JA, Bedworth L, Fencl AL (2017) Gauging climate preparedness to inform adaptation needs: local level adaptation in drinking water quality in CA. Climatic Change, USA. https://doi.org/10. 1007/s10584-01601870-3

Ekstom JA, Klasic MR, Fencl AL, Lubell M, Baker Z, Einterz F (2018) Drought Management and Climate Adaptation of Small, Self-Sufficient Drinking Water Systems in California'. A Report for California's Fourth Climate Change Assessment. https://www.energy.ca.gov/sites/default/files/201912/Water_CCCA4-CNRA-2018-004_ada.pdf

Engle NL (2011) Adaptive capacity and its assessment. Global Environmental Change: Human and Policy Dimensions 21(2):647-656. https://doi.org/10.1016/j.gloenvcha.2011.01.019

Engle NL (2012) Adaptation bridges and barriers in water planning and management: insight from recent extreme droughts in Arizona and Georgia. Journal of the American Water Resources Association 48:1139-1150. https://doi.org/10.1111/j.1752-1688.2012.00676.x

Engle NL (2013) The role of drought preparedness in building and mobilizing adaptive capacity in states and their community water systems. Clim Chang 118:291-306. https://doi.org/10.1007/s10584-012-0657-4

Francis R, Firestone L (2010) Implementing the human right to water in California's Central Valley: building a democratic voice through community engagement in water policy decision making. Willamette L Rev 47:495-538

Garrick DE, Schlager E, Stefano LD, Villamayor-Tomas S (2018) Managing the cascading risks of droughts: institutional adaptation in transboundary river basins. Earth's Future 6:809-827. https:// doi.org/10.1002/2018EF000823

Griffin D, Anchukaitis KJ (2014) How unusual is the 2012-2014 California drought? Geophys Res Lett 41:9017-9023. https://doi.org/10.1002/2014GL062433

Herman-Mercer NM, Matkin E, Laituri MJ, Toohey RC, Massey M (2016) Changing times, changing stories: generational differences in climate change perspectives from four remote indigenous communities in Subarctic Alaska. Ecol Soc 21(3):28

Hornberger GM, Hess DJ, Gilligan J (2015) Water conservation and hydrological transitions in cities in the United States. Water Resour Res 51:4635-4649

Imperial MT (1999) environmental justice and water pollution control: the clean water act construction grants program. Public Works Manag Policy 4:100-118. https://doi.org/10.1177/1087724X99 42003

Jasechko S, Perrone D (2020) California's Central Valley groundwater wells run dry during recent drought. Earth's Future. https://doi.org/10.1029/2019EF001339 
Kates RW, Travis WR, Wilbanks TJ (2012) Transformational adaptation when incremental adaptations to climate change are insufficient. PNAS 109:7156-7161

London J, Huang G, Zagofsky T (2011) Land of risk, land of opportunity. UC Davis Center for Regional Change

London J, Fencl, AL, Watterson S, Jarin J, Seaton P, Dawson M et al (2021) Disadvantaged unicoprorated communities, informality and the struggle for water justice. Water Alternatives

Luyet V, Schlaepfer R, Parlange MB, Buttler A (2012) A framework to implement stakeholder participation in environmental projects. J Environ Management 111:213-219. https://doi.org/10.1016/j. jenvman.2012.06.026

Marsh B, Parnell AM, Joyner AM (2010) Institutionalization of racial inequality in local political geographies. Urban Geogr 31:691-709. https://doi.org/10.2747/0272-3638.31.5.691

Mastrandrea MD, Heller NE, Root TL, Schneider SH (2010) Bridging the gap: linking climate-impacts research with adaptation planning and management. Clim Chang 100:87-101. https://doi.org/10. 1007/s10584-010-9827-4

McFarlane K, Harris LM (2018) Small systems, big challenges: review of small drinking water system governance. Environ Reviews. https://doi.org/10.1139/er-2018-0033

McNeeley SM (2014) A "toad's eye" view of drought: regional socio-natural vulnerability and responses in 2002 in Northwest Colorado. Regional Environ Change 14:1451-1461. https://doi.org/10.1007/ s10113-014-0585-0

McNeeley SM, Beeton TA, Ojima DS (2016) Drought risk and adaptation in the interior United States: understanding the importance of local context for resource management in times of drought. Weather, Clim, and Society 8:147-161. https://doi.org/10.1175/WCAS-D-15-0042.1

Measham TG, Preston BL, Smith TF, Brooke C, Gorddard R, Withycombe G, Morrison C (2011) Adapting to climate change through local municipal planning: barriers and challenges. Mitig Adapt Strateg Glob Change 16:889-909. https://doi.org/10.1007/s11027-011-9301-2

Méndez-Barrientos LE, DeVincentis A, Rudnick J, Dahlquist-Willard R, Lowry B, Gould K (2020) Farmer participation and institutional capture in common-pool resource governance reforms. The Case of Groundwater Management in California 33(12):1486-1507

Moser SC, Ekstrom JA (2010) A framework to diagnose barriers to climate change adaptation. PNAS 107(51):22026-22031. https://doi.org/10.1073/pnas.1007887107

Moser SC, Ekstrom JA, Kim J, Heitsch S (2018) Adaptation finance archetypes: Local governments' persistent challenges of funding adaptation to climate change and ways to overcome them. Ecol Soc 24(2):28. https://doi.org/10.5751/ES-10980-240228

Næss LO, Bang G, Eriksen S, Vevatne J (2005) Institutional adaptation to climate change: flood responses at the municipal level in Norway. Glob Environ Chang 15:125-138. https://doi.org/10.1016/j.gloenvcha. 2004.10.003

Newsom G (2021) State of emergency proclamation. Signed April 21, 2021. https://www.gov.ca.gov/wpcontent/uploads/2021/04/4.21.21-Emergency-Proclamation-1.pdf

Office of the Governor (2021a) Governor Newsom signs climate action bills, outlines historic $\$ 15$ billion package to tackle the climate crisis and protect vulnerable communities. https://www.gov.ca.gov/2021/ 09/23/governor-newsom-signs-climate-action-bills-outlines-historic-15-billion-package-to-tackle-theclimate-crisis-and-protect-vulnerable-communities/

Office of the Governor (2021b) Governor Newsom announces $\$ 5.1$ billion package for water infrastructure and drought response as part of $\$ 100$ billion California comeback plan. In: California Governor. https://www.gov.ca.gov/2021/05/10/governor-newsom-announces-5-1-billion-package-for-water-infra structure-and-drought-response-as-part-of-100-billion-california-comeback-plan/. Accessed 16 Jun 2021

Page R, Dilling L (2020) How experiences of climate extremes motivate adaptation among water managers. Clim Change 161:499-516. https://doi.org/10.1007/s10584-020-02712-7

Pauloo R, Dahlke H, Escriva-Bou A, Fencl AL, Guillon H, Fogg G (2020) Domestic well vulnerability to drought in California's Central Valley. Environ Res Lett. https://doi.org/10.1088/1748-9326/ab6f10

Rossi G, Cancelliere A (2013) Managing drought risk in water supply systems in Europe: a review. International J of Water Resources Development 29:272-289. https://doi.org/10.1080/07900627.2012.713848

Saldaña J (2013) The coding manual for qualitative researchers. SAGE Publications

Seager R, Hoerling M, Schubert S, Wang H, Lyon B, Kumar A, Nakamura J, Henderson N (2015) Causes of the 2011-14 California drought. J Clim 28:6997-7024. https://doi.org/10.1175/JCLI-D-14-00860.1

Shi L, Chu E, Anguelovski I, Aylett A, Debats J, Goh K, Schenk T, Seto KC, Dodman D, Roberts D, Roberts JT, VanDeveer SD (2016) Roadmap towards justice in urban climate adaptation research. Nature Clim Change 6:131-137. https://doi.org/10.1038/nclimate2841 
Swain DL, Langenbrunner B, Neelin JD, Hall A (2018) Increasing precipitation volatility in twenty-firstcentury California. Nature Clim Change 8:427-433. https://doi.org/10.1038/s41558-018-0140-y

SWRCB (2014) Electronic annual report (EAR) data from public drinking water systems. 2014RY. California State Water Resources Control Board. https://www.waterboards.ca.gov/drinking_water/certlic/ drinkingwater/eardata.html

SWRCB (2016) state water resources control board posts 36-Month Urban Water Supply Stress Test Submissions. California State Water Resources Control Board. https://www.waterboards.ca.gov/water_ issues/programs/conservation_portal/docs/emergency_reg/fs81616_stress_test.pdf

SWRCB (2021) Safe and affordable funding for equity and resilience. In: SAFER Drinking Water. California State Water Resources Control Board. https://www.waterboards.ca.gov/safer/. Accessed 1 Jul 2021

U.S. Bureau of Reclamation (2021) About the Central Valley Project. USBR. https://www.usbr.gov/mp/cvp/ about-cvp.html

U.S. Census Bureau (2016) 2012-2016 ACS 5-yr Summary. https://www.census.gov/programs-surveys/acs/ technical-documentation/table-and-geography-changes/2016/5-year.html

U.S. EPA (2021) Learn about capacity development. United States Environmental Protection Agency. https:// www.epa.gov/dwcapacity/learn-about-capacity-development

Victor D (2015) Climate change: Embed the social sciences in climate policy. Nature 520:27-29. https://doi. org/10.1038/520027a

Wilhite D, Pulwarty RS (2017) Drought and water crises: integrating science, management, and policy, 2nd edn. CRC Press. https://doi.org/10.1201/b22009

Williams AP, Seager R, Abatzoglou JT, Cook BI, Smerdon JE, Cook ER (2015) Contribution of anthropogenic warming to California drought during 2012-2014. Geophys Res Lett 42:6819-6828. https://doi. org/10.1002/2015GL064924

Publisher's Note Springer Nature remains neutral with regard to jurisdictional claims in published maps and institutional affiliations. 